\title{
Properties of Polymer-Composite Used as Fills of Asian Lacquerware: Issues on Restoration Processes of Lacquered Objects from Cultural Heritage
}

\author{
Anne-Solenn Le Hô, ${ }^{1}$ Isabelle Fabre-Francke, ${ }^{2}$ and Caroline Thiphavong ${ }^{3}$ \\ ${ }^{1}$ Centre de Recherche et de Restauration des Musées de France (C2RMF), Ministère de la Culture et de la Communication, \\ Palais du Louvre-Porte des Lions, 14 quai François Mitterrand, 75001 Paris, France \\ ${ }^{2}$ Laboratoire de Physicochimie des Polymères et des Interfaces (LPPI), Institut des Matériaux, Université de Cergy-Pontoise, \\ 5 mail Gay-Lussac, Neuville-sur-Oise, 95031 Cergy-Pontoise Cedex, France \\ ${ }^{3}$ Institut National du patrimoine (INp), Département des Restaurateurs, 150 avenue du Président Wilson, \\ 93210 Saint Denis La Plaine, France
}

Correspondence should be addressed to Anne-Solenn Le Hô; anne-solenn.leho@culture.gouv.fr

Received 29 January 2015; Revised 16 June 2015; Accepted 25 June 2015

Academic Editor: Michael Schilling

Copyright ( 2015 Anne-Solenn Le Hô et al. This is an open access article distributed under the Creative Commons Attribution License, which permits unrestricted use, distribution, and reproduction in any medium, provided the original work is properly cited.

\begin{abstract}
One of the common problems encountered in lacquerware issued from cultural heritage is the appearance of lifting areas and some losses of material. Composite systems made of commercial polymer and different fills were tested as filling agents for the cracking, splitting, and losses compensation of Asian lacquer. For that purpose, the stability of traditional and modern commercially available materials usually used in the restoration practice of historical lacquerware was assessed. Their thermomechanical and chemical properties and surface state were evaluated by a set of techniques (TGA, DMA, mechanical test, contact angle value, and microtopography). There is a drastic change of the behavior of the interface between fill and Asian lacquer, dependent on the nature of the composite fillers. So the evaluation of materials and processes for the restoration of Asian lacquer were emphasized. The commercial Paraloid B72 used with glass microspheres as additives appeared to be the most stable of all of the investigated fillers.
\end{abstract}

\section{Introduction}

Asian lacquer is one of the most important materials and practices in the history and culture of oriental civilization from the Neolithic to nowadays. Concurrently lacquerware is one of the leading contributors of Far East in the cultural heritage, especially decorative arts, in the Europe. The objects constitutive of Asian lacquer were largely imported from East Asia to Europe from the sixteenth century by maritime routes as luxury and exotic products. So they are now largely widespread in Occidental museum collections. Even though it is considered as an ideal natural, durable, and plastic coating, lacquer can suffer from substantial damage, mainly caused by improper reparation, its poor UV stability, and its brittleness under dry conditions. The poor UV stability and the brittleness of lacquer cause permanent mechanical damage such as cracking, lifting, and losses of material within substrate or lacquer layers. Once cracks have been formed, they evolve from the lacquer surface to the ground preparation and finally to the substrate. The lacquer splits away from the substrate. These common problems are commonly encountered in the Occident where the climate is often dryer than in Asia [1-4].

In the last past decades, different treatments were experimented in the Occident to fill exfoliation and losses of lacquer. To repair these structural deteriorations, fills are applied to lacquer in order to penetrate into losses of lacquer and complete voids. Nevertheless, lacquer can be a difficult material to work for Western conservators because the lacquer technology poorly migrated from Asia to West. Furthermore, 
lacquer is not a reversible material. In the Western museum conservation-restoration principle, repairs appear acceptable if they are compatible with the original ones and can be removed easily without causing damage. So the Asian traditional practice with the use of materials based on lacquer, as kokuso-a mixture of lacquer, cotton or hemp fibers, and wood powder-to fill holes, gaps, and cracks is almost not considered in Western museums. This concept of reversibility of conservation treatments is a central motivation in the Occident [5]. For that reason, Western conservators have adopted the use of synthetic or even other natural fillers instead of the traditional Asian lacquer fillers. In the last 20 years, a lot of fill materials were experimented based on waxes (beeswax, microcrystalline, paraffin, and carnauba), dammar terpenic resin, or modern synthetic compounds such as polyester resin, polyvinyl alcohol, and epoxy resin [6]. Nevertheless various problems can be encountered as thermochromatic changes, brittleness of the filler, or a lack of reversibility.

This paper deals with fills for cracks and losses, even the deeper and largest ones occurring from the surface to the substrate. These ones are the most problematic to repair. The goal of this work was not to prescribe a fill recipe or application method but rather to provide useful comparative data to aid in choosing different fillers and lacquer loss compensation treatments. With greater knowledge of the properties of filler compounds, it may be possible to better control the filler. So the significant factor guiding this research was detailed; then the properties of materials commonly used by conservators for restoration of lacquer were studied. Our strategy was to measure and compare performances and characteristics of restoration material by a set of thermophysical and chemical techniques to have a better assessment. With this in mind, extensive testing of different fills was chosen to go beyond aesthetic observations and visual considerations.

An appropriate fill has to balance characteristics to attain the best combination of strength, adhesive compatibility, nominal shrinkage, retreatability, stability, and aesthetic compensation [6-8].

Thus the thermomechanical, chemical, and optical properties of a set of synthetic and natural fills were characterized with the purpose of evaluating the fillers used in the restoration of lacquerware. Fillers made of copolymer of acrylate and methacrylate, polyvinyl alcohol, hydroxypropyl cellulose, or vegetal, mineral waxes, and terpenic resin were tested.

The behavior of the tested filler mixture was compared with the original material to fill in (lacquer or ground layer) by an analytical methodology: thermal analyses by TGA and DMA to test the stability of fills, mechanical tests to investigate their strength properties, contact angle values to characterize their hydrophobic or hydrophilic properties and solubility measurements.

The roughness is a key optical parameter on appearance phenomena. The more the fill is rough, the more matt, scarred, and imperfect the treated surface will appear. This will lead to changes in gloss and color saturation in the surface finishes (final surface of the fill and top coat). Furthermore, adhesion is dependent on chemistry and also roughness of the surfaces to be adhered.
So the overall appearance of the treated surface was also investigated by microtopography to measure the roughness of the fills.

\section{Experimental}

2.1. Sample Preparation. The selection of these filler materials was based on products and recipes usually described in the literature and used in the lacquer restoration practice in the Occident $[6,9,10]$. A preliminary survey has been made addressed to Western lacquer conservators to take an inventory of filler materials and processes that are in common used to compensate for losses on lacquer.

Five polymer-composite fills were chosen from among those typically used in art restoration of lacquer. The composition of the different filler materials is given in Table 1. Paraloid B72 (ethyl methacrylate and methyl acrylate copolymer) (Rhom and Haas), Gelvatol (polyvinyl alcohol) (CTS), Klucel G/CaCO 3 (hydroxypropyl cellulose) (Stouls), ethanol (VWR, GPR Rectapur 95-97\%), acetone (VWR, technical), phenolic micro balls $(20-90 \mu \mathrm{m}$ in size, CTS), micro glass beads Scotchlite K-15 (size between 30 and $80 \mu \mathrm{m}, 3 \mathrm{M}$ ), carnauba wax (La Cérésine), $\mathrm{CaCO}_{3}$ (Sennelier). Dammar resin, ozokerite, and talcum were taken from the laboratory of the restoration department at the Institut National du patrimoine (Saint-Denis).

The fills were prepared similarly to common restoration practices and using similar conditions. Most of the composite fills were obtained by stirring each of the compounds at room temperature. The carnauba wax/dammar resin filling was the only one to be prepared at $90^{\circ} \mathrm{C}$. The obtained mixtures were then poured into a silicone mould, measuring $2 \mathrm{~cm} \times 3 \mathrm{~cm} \times$ $0.5 \mathrm{~cm}$. For DMA, films of fills were prepared in moulds of smaller size. Typical dimensions of the DMA samples were $6 \mathrm{~mm} \times 20 \mathrm{~mm} \times 1 \mathrm{~mm}$ (Figure 1). Then they were dried at laboratory temperature and $40-50 \%$ RH under free air for 12 hours, except for the mixture wax/resin which was dried for few minutes.

For microtopography, fills were successively polished with $240,600,800,1600$, and 3600 grade Micro-Mesh ( abrasive cloth [11]. Then the surface roughness was measured on polished fills.

Furthermore one Asian traditional material was also tested as reference of original compound encountered in lacquerwares. This reference was prepared using a real Asian processing method. A kuro-nakanuri lacquer, originated from China and processed in Japan, was selected (Watanabe Syoten, Tokyo, Japan). The kuro-nakanuri is usually used for intermediate layers of lacquer and made by the adding of black pigments to lacquer. A reference of kuro-nakanuri lacquer was prepared by the restorer. Five layers of kuronakanuri were successively applied with a paintbrush onto a silicone plate.

The Paraloid PB72 is used as an extremely stable and nonyellowing polymer on internal exposure in a gallery $[12,13]$. $\mathrm{PVA} / \mathrm{CaCO}_{3}$ can be applied easily, dries quickly, and can also be burnished to a very smooth finish [6]. It is stable under light, and its yellowing occurs beyond $80^{\circ} \mathrm{C}$. Klucel G/CaCO seems a good candidate for its strong adhesive properties. It 
TABLE 1: Composition of fills.

\begin{tabular}{|c|c|c|c|}
\hline Fills & \multicolumn{3}{|c|}{ Percentage of each compound (\% in weight) } \\
\hline $\mathrm{PB} 72 / \mu$ phenolic balls & $\begin{array}{l}75 \% \text { of PB72 in } 25 \% \text { of ethanol/ } \\
\text { acetone (1/1) solution }\end{array}$ & $25 \%$ of phenolic micro balls & \\
\hline $\mathrm{PB} 72 / \mu$ glass beads & $\begin{array}{l}90 \% \text { of } \mathrm{PB} 72 \text { in } 25 \% \text { of ethanol/ } \\
\text { acetone (1/1) solution }\end{array}$ & $10 \%$ of glass bubbles Scotchlite & \\
\hline $\mathrm{PVA} / \mathrm{CaCO}_{3}$ & $25 \%$ of Gelvatol in $8 \%$ of $\mathrm{H}_{2} \mathrm{O}$ & $75 \%$ of $\mathrm{CaCO}_{3}$ & \\
\hline Klucel G/CaCO${ }_{3}$ & $40 \%$ of Klucel $\mathrm{G} / \mathrm{CaCO}_{3}$ in $6 \%$ of ethanol & $60 \%$ of $\mathrm{CaCO}_{3}$ & \\
\hline Wax/resin & $23 \%$ of carnauba wax & $30 \%$ of dammar resin & $23 \%$ of ozokerite \\
\hline
\end{tabular}

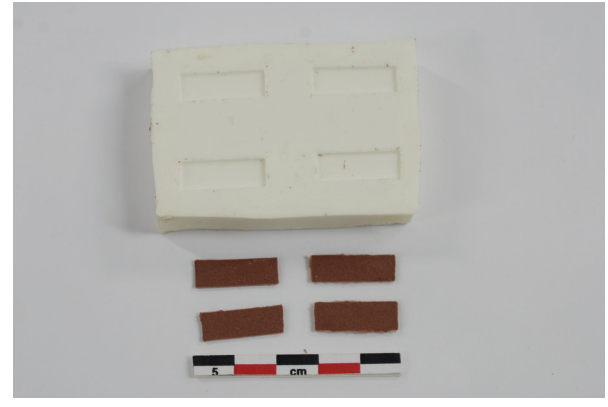

FIGURE 1: Fills after preparation in moulds.

is used for leather and pigment consolidation [14, 15]. The wax/resin is commonly used because it is easy to spread.

2.2. Accelerated Ageing. Samples of fillers were submitted to accelerate thermal ageing to evaluate their stability. The samples were submitted to $60^{\circ} \mathrm{C}$ for 113 hours at $85 \%$ relative humidity and $10^{\circ} \mathrm{C}$ for 168 hours and $20 \%$ relative humidity, in an APT Line KBF WTB Binder climatic chamber. Samples were removed after the ageing to perform their physicochemical measurements.

2.3. Physicochemical Measurements. The thermal techniques used for the evaluation of fills were thermogravimetric analysis (TGA) and dynamic mechanical thermal analysis (DMTA) because these techniques are sensitive to changes in ageing of materials. The selected ranging temperature (room temperature to $250^{\circ} \mathrm{C}$ ) gives accurate indication of the inherent mechanical and chemical properties of the fills (softness, stiffness, molecular nature, movements of structure, etc.). The ability of the polymer chains to move past one another and adjust to a changed situation (mobility of chains, movements of molecular structure) may be also tested. The ranging temperature is an ideal way to test material and polymer for conservation purposes. It allows an evaluation of their properties.

Thermogravimetric analysis (TGA) was performed on a TGA Q50 model (TA Instruments) under synthetic air $\left(60 \mathrm{~mL} \cdot \mathrm{min}^{-1}\right)$ from room temperature to $250^{\circ} \mathrm{C}$, at $5^{\circ} \mathrm{C} \cdot \mathrm{min}^{-1}$ heating rate.

DMA measurements were carried out on sample films with a Q800 apparatus (TA Instruments) operating in tension mode. Experiments were performed at a frequency of $1 \mathrm{~Hz}$ and heating rate of $5^{\circ} \mathrm{C} \cdot \mathrm{min}^{-1}$ from 35 to $250^{\circ} \mathrm{C}$. Typical dimensions of the samples were $6 \mathrm{~mm} \times 20 \mathrm{~mm} \times 1 \mathrm{~mm}$. The setup provides the storage and loss modulus ( $E^{\prime}$ and $\left.E^{\prime \prime}\right)$ and the damping parameter or loss factor is defined as $\tan \delta=E^{\prime \prime} / E^{\prime}$. In fact the loss factor $\tan \delta$ is the ratio of loss modulus to storage modulus. It is a measure of the energy loss, expressed in terms of the recoverable energy, and represents mechanical damping or internal friction in a viscoelastic system. The loss factor $\tan \delta$ is expressed as a dimensionless number. A high $\tan \delta$ value is indicative of a material that has a high, nonelastic strain component, while a low value indicates a more elastic material. The storage data was normalized at $1000 \mathrm{MPa}$ at $35^{\circ} \mathrm{C}$.

Shearing tests were performed on Instron 1122 with applied force to $5 \mathrm{KN}$ at room temperature with a rate of deformation of $0.5 \mathrm{~mm} \cdot \mathrm{m}^{-1}$. These tests lead to study the adhesion and the resistance to failure of different composite fills. The shear was applied to the fill in the plane of the bond line. Typical dimensions of the samples were $20 \mathrm{~mm} \times 10 \mathrm{~mm}$. Sandwich specimens made for the tests constituted of two plates of beech between which was disposed filling material of $0.5 \mathrm{~mm}$ thickness. These specimens modeled infilling of extensive and large losses that penetrate deep into the object, that is, from the lacquer surface to wooden substrate of lacquerware. They modeled wooden substrate with losses of lacquer where a fill is required to bulk out large voids and fill losses in the surface and deeper areas. It means the fills but also the surrounding wood and their compatibilities were tested. The influence of the fill on the response of wooden substrate was also appreciated.

Contact angle measurements were performed using a DSA-P instrument (Kruss, Germany) and water. It is of prime importance to perform contact angle measurements with water. A main factor in the deterioration of Asian lacquer is its sensitivity to water. The surface of damaged lacquer may be soluble. Aqueous substances also cause discoloration. Lacquer should be exposed to water if preliminary tests have been carried out. Asian lacquer is often coated onto a number of layers (substrate, ground, and finishing layers). In many cases, many of these layers are water-soluble. The sensitive nature of lacquer to water must be taken into account during filling losses. Additionally, hygroscopic fillers may allow the fill to contract or expand with varying relative humidity.

One drop of water $(25 \mu \mathrm{L}$, Millipore Ultrapure) was deposited on each polymer-composite sample. The static contact angle was measured by means of a Young-Laplace drop 
profile fitting. The reported values correspond to the average of three measurements with an error bar corresponding to the standard deviation.

Microtopography was carried out on a station of STIL micromeasurements (model Micromesure) equipped with a CHR 150-N high resolution optical sensor. This nondestructive technique allows, starting from measurements of altitude variations, the calculation of the roughness of a surface at the microscale [4]. It is one of the very few noncontact techniques for 3D metrology recommended by the ISO 25178 international standard.

The selected parameters were as follows: optical pen $3000 \mu \mathrm{m}$, frequency of $300 \mathrm{~Hz}$, scanned surface over a distance of $2.5 \mathrm{~mm}$ ( $x$-axis) $\times 2.5 \mathrm{~mm}$ ( $y$-axis), rate of $1000 \mu \mathrm{m} \cdot \mathrm{s}^{-1}$, and step size of $10 \mu \mathrm{m}$ on $x$ - and $y$-axis. The two-dimensional root-mean-square deviation of the profile, $R_{q}$, which demonstrates the root-mean-square value of the profile deviation compared to the line of reference of least squares, is expressed as:

$$
R_{q}=\mathrm{RMS}=\sqrt{\frac{1}{N} \sum_{i=1}^{N} y_{i}^{2}}
$$

where $N$ represents the number of deviations taken into account.

\section{Results and Discussion}

3.1. Thermogravimetric Analysis. Thermogravimetric study of unaged fills was done. In order to study their thermal stability, the measurements were performed up to $250^{\circ} \mathrm{C}$. As shown in Figure 2, all materials are stable up to $100^{\circ} \mathrm{C}$ and no weight loss is observed. A significant weight loss of $15 \%$ can be observed starting from $100^{\circ} \mathrm{C}$ for $\mathrm{PVA} / \mathrm{CaCO}_{3}$. This mass loss, which is water loss, is most likely due to the presence of water during the material preparation and can be observed up to $100^{\circ} \mathrm{C}$. Furthermore a continuous weight loss is observed for the PB72/ $\mu$ phenolic ball fill probably due to the presence of solvent or monomer. Other materials are relatively stable up to $250^{\circ} \mathrm{C}$.

In addition, a reference material was also analyzed under the same conditions, that is, a reference to the corresponding kuro-nakanuri lacquer. A mass loss of less than $5 \%$ was observed up to $250^{\circ} \mathrm{C}$ corresponding to the water used during the preparation of the sample. All of these materials are therefore stable in the 25 to $250^{\circ} \mathrm{C}$ temperature range.

Then, aged fills were also studied (Figure 3). In general, the aged materials have the same behavior as the unaged ones except $\mathrm{PVA} / \mathrm{CaCO}_{3}$. Indeed, no mass loss was observed in aged material. For PVA/CaCO 3 , thermal ageing causes the elimination of volatile species, along with the removal of the preparation residual water.

All of these measurements show that polymer-composite fills and lacquer reference are relatively stable for use and storage between ambient temperature and $250^{\circ} \mathrm{C}$. Moreover the accelerated ageing of these materials has no noticeable effect on their thermal stability. In conclusion, at this point

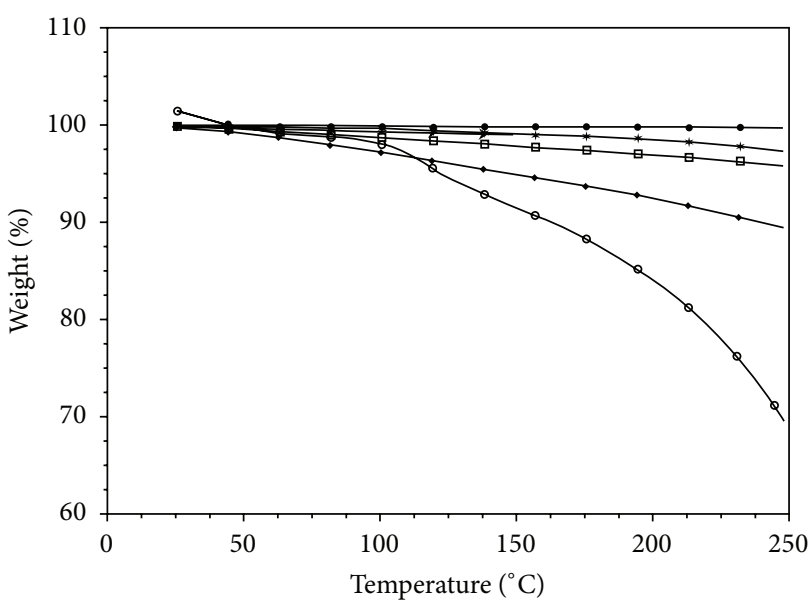

Figure 2: Behavior of weight loss for different unaged fills and reference: $(\bullet)$ Klucel $\mathrm{G} / \mathrm{CaCO}_{3},(\diamond) \mathrm{PB} 72 / \mu$ phenolic balls, (*)

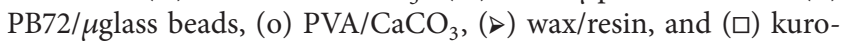
nakanuri lacquer.

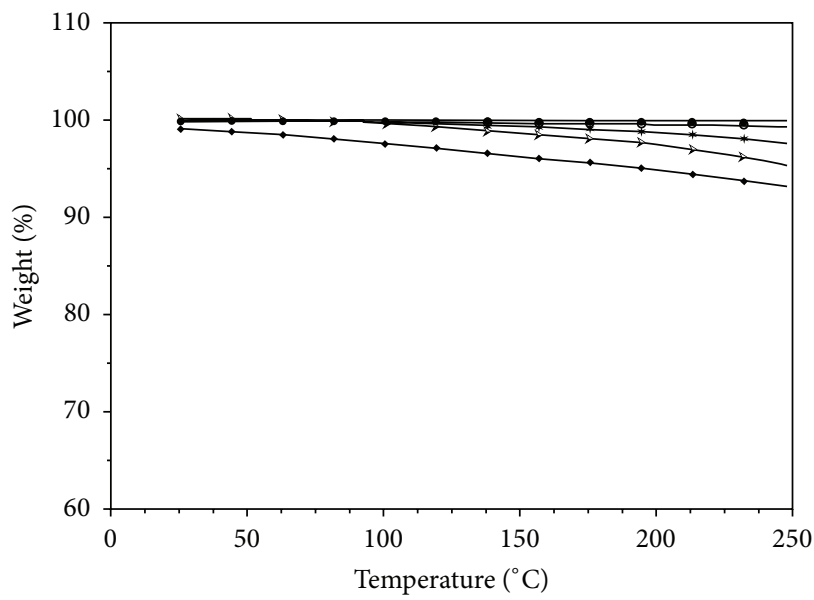

Figure 3: Weight loss of aged fills: $(\bullet)$ Klucel $\mathrm{G} / \mathrm{CaCO}_{3},(\diamond)$

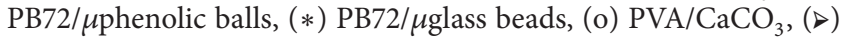
wax/resin, and ( $\square)$ kuro-nakanuri lacquer.

of the study, it is difficult to promote a filler system compared to another.

3.2. Dynamic Mechanical Analysis (DMA). DMA measurements were performed on unaged materials. Loss factor $(\tan \delta)$ and storage moduli $\left(E^{\prime}\right)$ are represented between ambient and about $250^{\circ} \mathrm{C}$ temperature in Figures 4 and 5 . The maximum of loss factor corresponds to the $\alpha$ mechanical relaxation. The storage modulus $E^{\prime}$ is characteristic of the rigidity of the material, and this study used to compare the strength of the various fills.

Depending on the composition of the materials, some samples were not analyzed by this technique because of their fragility and brittleness: wax/resin which was very breakable, PVA/ $\mathrm{CaCO}_{3}$ with a high percentage of charges $(75 \%$ of $\mathrm{CaCO}_{3}$ ) influencing the mechanical properties of the filler compound and making it brittle. 


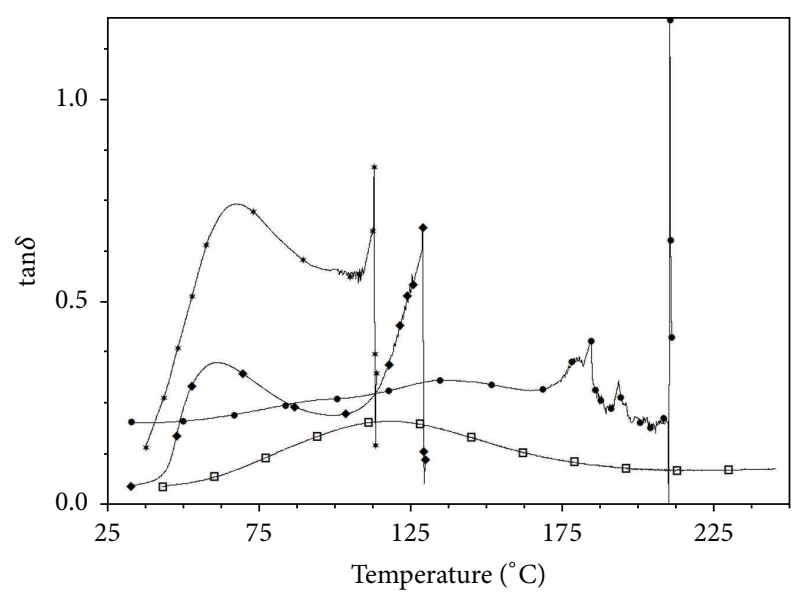

FIGURE 4: Mechanical relaxation temperature and loss factor of

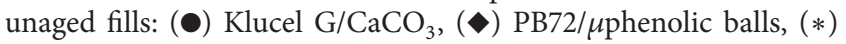
PB72/ $\mu$ glass beads, and ( $\square$ ) kuro-nakanuri lacquer.

The reference kuro-nakanuri lacquer shows a $\alpha$ mechanical relaxation temperature $(T \alpha)$ of $119^{\circ} \mathrm{C}$ in Figure 4. Both of mixtures polyacrylates PB72/ $\mu$ phenolic balls and PB72/ $\mu$ glass beads have $T \alpha$ of $56^{\circ} \mathrm{C}$ and $66^{\circ} \mathrm{C}$, respectively. These mechanical relaxation temperatures are in the range of values usually measured for non-cross-linked acrylate polymers [16]. Finally, the Klucel $\mathrm{G} / \mathrm{CaCO}_{3}$, a cellulose derivative, was described as having complicated thermomechanical spectra and damping at room temperature was distinctly higher than that of the other polymers [17]. The Klucel $\mathrm{G} / \mathrm{CaCO}_{3}$ fill does not exhibit a very marked mechanical relaxation. Only a small relaxation was detected at about $136^{\circ} \mathrm{C}$ with the presence of a shoulder at $100^{\circ} \mathrm{C}$. This material is very rigid in a broad temperature range.

Figure 3 also presents maximal values of $\tan \delta$ at 0.21 , $0.31,0.36$, and 0.74 , respectively, for kuro-nakanuri lacquer reference, Klucel $\mathrm{G} / \mathrm{CaCO}_{3}, \mathrm{~PB} 72 / \mu$ glass beads, and PB72/ $\mu$ phenolic balls. PB72/ $\mu$ phenolic balls have a high, nonelastic strain component contrary to the other fills and lacquer.

The values of storage moduli at $35^{\circ} \mathrm{C}$ are, respectively, 231, 393, 648, and $1034 \mathrm{MPa}$ for PB72/ $\mu$ glass beads, PB72/ $\mu$ phenolic balls, Klucel G/CaCO${ }_{3}$, and kuro-nakanuri lacquer reference. This result confirms that the $\mathrm{Klucel} \mathrm{G} / \mathrm{CaCO}_{3}$ is the most rigid material after the lacquer.

Secondly, all moduli were normalized to $1000 \mathrm{MPa}$ at $35^{\circ} \mathrm{C}$ in order to be compared (Figure 5). Some materials have poor mechanical properties due to creep. The latter corresponds to the sliding of the polymer chains with respect to each other to break the material. This break is reflected by a significant drop in the storage modulus. At the same time, it is translated by the increase of $\tan \delta$ (Figure 4 ). Indeed the value of $\tan \delta$ varies from $0.31-0.36$ to 1 for the Klucel $\mathrm{G} / \mathrm{CaCO}_{3}$ and $\mathrm{PB} 72 / \mu$ glass and from 0.74 to 1.5 for $\mathrm{PB} 72 / \mu$ phenolic balls. This is not observed for lacquer. The kuro-nakanuri lacquer does not creep unlike PB72/ $\mu$ phenolic balls, PB72/ $\mu$ glass beads, and Klucel $\mathrm{G} / \mathrm{CaCO}_{3}$. Thus the highly cross-linked lacquer will become more malleable from $T \alpha=119^{\circ} \mathrm{C}$ but not even flow if the temperature reaches $250^{\circ} \mathrm{C}$. Polyacrylate materials, respectively, flow to about $116^{\circ} \mathrm{C}$ for the PB72/ $\mu$ phenolic balls and $102^{\circ} \mathrm{C}$ for the $\mathrm{PB} 72 / \mu$ glass beads while the Klucel $\mathrm{G} / \mathrm{CaCO}_{3}$ creep temperature is around $172^{\circ} \mathrm{C}[18,19]$. A leading factor for the difference between two fills made of PB72 is likely the nature and the proportion of particle volume fraction in the dried material. Indeed there are $25 \%$ of $\mu$ phenolic balls and $10 \%$ of $\mu$ glass beads, respectively, in PB72/ $\mu$ phenolic balls and PB72/ $\mu$ glass beads. The density of the two charges is close according to the data suppliers, that is, $250 \pm 20 \mathrm{~g} \cdot \mathrm{L}^{-1}$ for the $\mu$ phenolic balls and $230 \pm 20 \cdot \mathrm{L}^{-1}$ for the $\mu$ glass beads. As the volume fraction of $\mu$ glass beads is lower (0.04\%) than $\mu$ phenolic balls $(0.11 \%)$, it explains the lower modulus curve.

Thermomechanical results thus show that Klucel $\mathrm{G} / \mathrm{CaCO}_{3}$ is the material which has properties that are closest to the kuro-nakanuri lacquer reference. However, polyacrylates are also interesting because they can also be applied at temperatures below $100^{\circ} \mathrm{C}$.

3.3. Shearing Test. A shearing test was carried out on the 8 wood-fill samples for each filler mixture. Table 2 displays the load at the break. The shearing tests aim to evaluate the mechanical behavior of fill. They also aim to evaluate the adhesion of the fill/wood system. The lacquer kuro-nakanuri reference was not tested because it is only used for more superficial levels.

All the tested fills showed a fragile behavior. Furthermore, all breaks were within the fills, except for one Klucel $\mathrm{G} / \mathrm{CaCO}_{3}$ specimen, indicating that they are strongly adhesive.

Concerning the wax/resin fill, no measurement could be obtained, because all the samples were easily fragmented into pieces before the test. It indicates this fill is more brittle than the other ones. This result confirms the DMA result.

Klucel $\mathrm{G} / \mathrm{CaCO}_{3}$ breaks at much less shearing load than the other tested fills but only two measurements were successful with this fill. In the other cases, the failure of the fill occurred before the test, indicating a weakness and stiffness.

$\mathrm{PVA} / \mathrm{CaCO}_{3}$ fill shows dispersed results with a high standard deviation, parallel to those obtained by DMA, because of the high proportion of carbonate charge. So as $\mathrm{CaCO}_{3}$ is the major component, it influences the mechanical properties of the fill.

The two fills made of Paraloid were consistently strong with an average failure point at $650 \mathrm{~N}$ and $754 \mathrm{~N}$, respectively, for PB72/ $\mu$ phenolic balls and PB72/ $\mu$ glass beads.

Previous shearing tests, not described in the present paper, were also carried out on test samples made of beechwood-filler compound-ground coating to the lacquer. The results were the same as the ones with the presented samples made of filler compound-beechwood.

These results show that three of the tested materials, that is, wax/resin, Klucel $\mathrm{G} / \mathrm{CaCO}_{3}$, and $\mathrm{PVA} / \mathrm{CaCO}_{3}$, are brittle or heterogeneous due to a high proportion of charge. So only the PB72 fills seem to be good candidates. The fills made of Paraloid B72 beads present a good adherence and fail first 


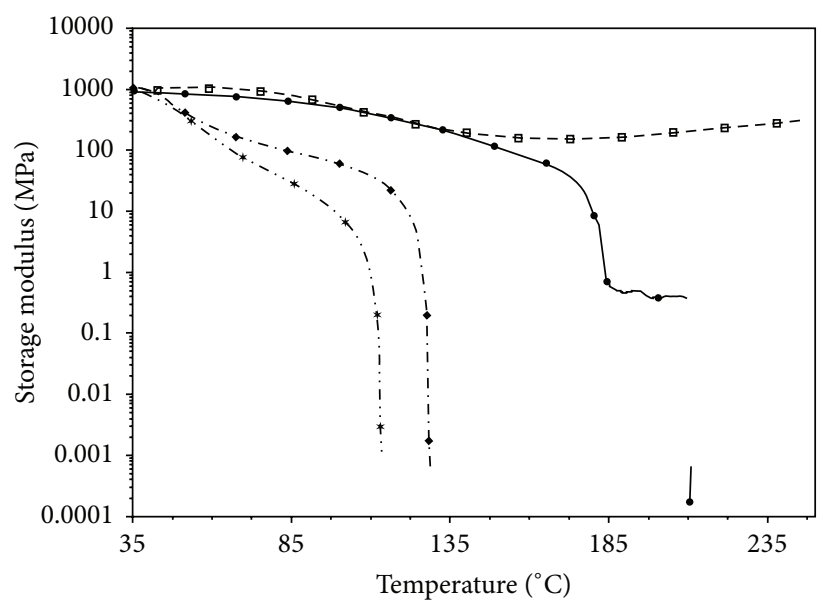

(a)

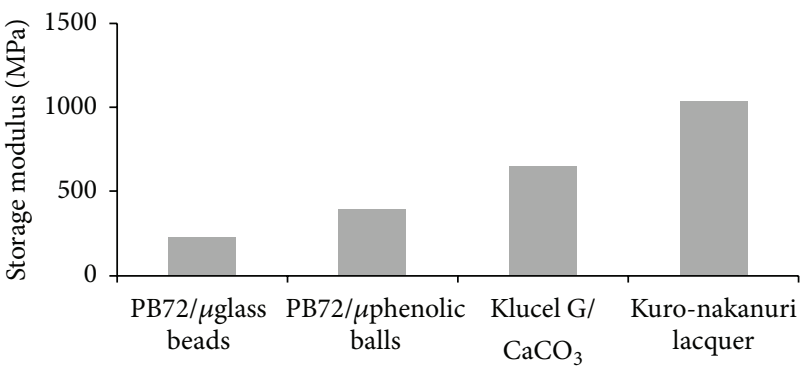

(b)

Figure 5: Storage modulus of unaged fills: $(\bullet)$ Klucel $\mathrm{G} / \mathrm{CaCO}_{3},(\diamond)$ PB72/ $\mu$ phenolic balls, $(*)$ PB72/ $\mu$ glass beads, and ( $\square$ ) kuro-nakanuri lacquer. (b) Storage modulus of fills normalized at $1000 \mathrm{MPa}, 35^{\circ} \mathrm{C}$, and $1 \mathrm{~Hz}$.

TABLE 2: Shearing load at break.

\begin{tabular}{|c|c|c|c|c|c|}
\hline Unaged fill & PB72/ $\mu$ phenolic balls & PB72/ $\mu$ glass beads & $\mathrm{PVA} / \mathrm{CaCO}_{3}$ & Klucel G/CaCO 3 & Wax/resin \\
\hline Number of samples broken before the test & 1 & 0 & 1 & 6 & 8 \\
\hline Average load at the failure $(\mathrm{N})$ & 650 & 754 & 453 & 153 & l \\
\hline Standard deviation & 60 & 26 & 107 & 3 & / \\
\hline
\end{tabular}

TABLE 3: Contact angle of a water drop on different polymercomposites.

\begin{tabular}{lcc}
\hline Polymer-composite & $\begin{array}{c}\text { Contact angle } \theta \\
\text { unaged material }\end{array}$ & $\begin{array}{c}\text { Contact angle } \theta \\
\text { aged material }\end{array}$ \\
\hline Wax/resin & $99^{\circ}$ & $98^{\circ}$ \\
PB72/ $\mu$ phenolic balls & $73^{\circ}$ & $72^{\circ}$ \\
PB72/ $\mu$ glass beads & $117^{\circ}$ & $113^{\circ}$ \\
Kuro-nakanuri lacquer & $79^{\circ}$ & $74^{\circ}$ \\
PVA/CaCO & Not measurable & Not measurable \\
Klucel G/CaCO & Not measurable & Not measurable \\
\hline
\end{tabular}

before beech. In all tests, no failure occurred in the wood. They also present the highest load at failure among all the fills.

3.4. Contact Angle. To evaluate the influence of the composition of the polymer-composite materials, the wetting properties were investigated by measuring contact angles (Table 3). It is important to have a filler material with the best property of wetting with respect to water, for example. The unaged and aged materials were tested to determine the stability of surface properties.

For $\mathrm{PVA} / \mathrm{CaCO}_{3}$ and Klucel $\mathrm{G} / \mathrm{CaCO}_{3}$ samples, the contact angle could not be measured as the water drop was instantly absorbed. PVA is a hydrophilic polymer which is dissolved in water [20]. Cellulose derivatives are usually known to be hydrophobic due to the presence of hydroxyl groups. Moreover, no measurement was expected due to the strong presence of inorganic charges in materials [21].
TABLE 4: Surface roughness, $R_{q}$.

\begin{tabular}{lc}
\hline Unaged Fill & $R_{q}(\mu \mathrm{m})$ \\
\hline Wax/resin & 0.48 \\
PB72/ $\mu$ phenolic balls & Not measurable \\
PB72/ $\mu$ glass beads & 10.9 \\
$\mathrm{PVA} / \mathrm{CaCO}$ & 3.9 \\
Klucel $\mathrm{G}_{3} \mathrm{CaCO}_{3}$ & 1.5 \\
Kuro-nakanuri lacquer (aged) & $0.9(3)$ \\
\hline
\end{tabular}

The contact angle values depend on the polymercomposite composition. Conversely, for other materials, the drop did not spread and was still not absorbed after several minutes. The contact angles are between $73^{\circ}$ and $117^{\circ}$ for the unaged composites. As the unaged kuro-nakanuri lacquer reference $\left(\theta=79^{\circ}\right)$, the unaged $\mathrm{PB} 72 / \mu$ phenolic balls are slightly hydrophilic $\left(\theta=73^{\circ}\right)$. In contrast, the wax/resin and PB72/ glass beads are hydrophobic with a contact angle of $99^{\circ}$ for the former and $117^{\circ}$ for the latter. The presence of micro glass beads provides a more pronounced hydrophobic character to the polymer-composite.

Indeed, it has been shown in various studies that the presence of micro glass beads in PMMA polymers increases their hydrophobicity. Thus, Pareo et al. showed that a PMMAbased composite material loaded with hollow glass microsized spheres has a hydrophobic behavior [22]. In the study by Chibowski et al., the advancing and receding contact angles of water were measured on PMMA/glass sphere hollows $\left(0.2 \mathrm{~g} \cdot \mathrm{cm}^{3}\right)$ deposited on glass surface by the spin 
TABLE 5: Overall properties of tested fills.

\begin{tabular}{|c|c|c|c|c|c|}
\hline & TGA test & DMA tests & Shearing tests & Contact angle & Roughness \\
\hline Klucel G/CaCO 3 & Stable & ++++ & + & + & ++++ \\
\hline PB72/ $\mu$ phenolic balls & Stable & +++ & ++++ & ++++ & ++ \\
\hline PB72/ $\mu$ glass beads & Stable & +++ & ++++ & +++ & l \\
\hline $\mathrm{PVA} / \mathrm{CaCO}_{3}$ & Stable & + & +++ & + & +++ \\
\hline Wax/resin & Stable & + & + & ++++ & ++++ \\
\hline
\end{tabular}

/ indicates the value was not measured.

+ indicates not satisfactory; ++ indicates moderately satisfactory; +++ indicates satisfactory; ++++ indicates highly satisfactory.

coating method [23]. A significant increase of $84^{\circ}$ in the measurement of contact angle was observed between PMMA and PMMA/glass sphere hollows with values of the advancing contact angles of $28^{\circ}$ for the former and $112^{\circ}$ for the latter.

Finally unaged and aged materials have the same behavior. Thus the study of the wettability of the surface shows that two different filler materials Klucel $\mathrm{G} / \mathrm{CaCO}_{3}$ and $\mathrm{PVA} / \mathrm{CaCO}_{3}$ are not advised in the field of heritage restoration because of their high hydrophilicity. Taking into account the mechanical properties of all materials, at this point of the study, the two materials $\mathrm{PB} 72 / \mu$ phenolic balls and $\mathrm{PB} 72 / \mu$ glass beads are susceptible to being able to respond to the expected specifications. PB72/ $\mu$ phenolic balls have a surface wettability similar to kuro-nakanuri lacquer reference while the PB72/ $\mu$ glass beads have markedly improved surface properties.

3.5. Microtopography. The final phase of testing was to measure the surface roughness of the fills. Table 4 presents the value of root-mean-square deviation, $R_{q}$.

The filler compounds exhibit different values. But considering the variety of the charges such as glass microspheres, phenolic microballoons, calcium carbonate, and their proportion, these results are not surprising.

Wax/resin and Klucel G/CaCO${ }_{3}$ exhibit smooth surfaces. The PB72/ $/$ phenolic balls could not be measured due to a diffusion of the light. This fill is usually used for deeper gaps and is covered by another superficial filler compound. So the absence of measurement is not problematic.

The $R_{q}$ value of the PB72/ $\mu$ glass beads is rather higher when compared to the other fills showing the influence of the granulometry of the micro glass beads.

Nevertheless, on the macroscopic scale, results less than or equal to 10 microns are all satisfactory and differences in $R_{q}$ among tested filler compounds are negligible. They are also in the same range as the one of lacquer [4]. It means all the tested fills present a $R_{q}$ value acceptable to be used without disfiguring the restored lacquerware.

\section{Discussion}

The aim of this research was to study the behavior of filler mixtures that are commonly used in the structural treatment of lacquerware.
In order to compare one fill to another easily, the results from the thermal tests, shearing tests wettability, and roughness are tabulated together (Table 5).

$\mathrm{PVA} / \mathrm{CaCO}_{3}$ is brittle and very sensitive to water, like Klucel $\mathrm{G} / \mathrm{CaCO}_{3}$, which may be inconsistent with conservation material. The fills made of Paraloid B72 meet basic criteria for conservation materials, that is, stability to humidity and temperature change in terms of stiffness, strength, resistance, and reversibility. Their lower rugosity compared to other fills is nevertheless satisfactory because it is out of the range of visual appreciation. In all tests, no wood damage occurred as failure was in the fill.

\section{Conclusion}

The aim was to compare the behavior of some representative materials of fillers used in the conservation-restoration of lacquerware. Fills were judged on their thermal, mechanic, and surface properties rather than qualitative factors of appreciation. The study yielded much useful information and revealed the limitations of several gap-filler materials.

All tested fills are stable from a thermal point of view. So they can be used as restoration materials of lacquerware in the cultural heritage. However, wax/resin and $\mathrm{PVA} / \mathrm{CaCO}_{3}$ appeared to be very brittle materials and they are not advised. In fact, the lacquerware can be submitted to dimensional variations, especially when the support is porous as wood, paper, bamboo, and so on. In such cases, these fills could not support the subsequent shrinkage or dilation.

Klucel $\mathrm{G} / \mathrm{CaCO}_{3}$ presents better mechanical properties, close to the kuro-nakanuri lacquer reference. Nevertheless, its wettability property is poor with a high hydrophilicity. It means the material cannot support ulterior cleaning interventions.

Finally fills made of ethyl methacrylate and methyl acrylate copolymer hold a strong potential. They are stable up to $250^{\circ} \mathrm{C}$ and easy to spread and are good adhesive. The PB72/ $\mu$ phenolic balls have a wettability similar to the kuro-nakanuri lacquer. The PB72/ $\mu$ glass beads present the advantage of high hydrophobicity. So these two fills show required criteria to be used in conservation-restoration of historical lacquer objects.

Future studies will need to be carried out to follow up the behavior of the treated Asian lacquerware with PB72/ $\mu$ phenolic balls and PB72/ $\mu$ glass beads. They will allow 
the full appreciation of the long-term stability of the fills under museum conditions.

\section{Disclosure}

This work was conducted as part of a diploma of restorer of heritage, furniture speciality, at the Institut National du patrimoine.

\section{Conflict of Interests}

The authors declare that there is no conflict of interests regarding the publication of this paper.

\section{Acknowledgments}

Anne Genachte-Le Bail and Sigrid Mirabaud of the Institut National du patrimoine are kindly acknowledged for their support. The authors acknowledge the support from the Laboratoire de Recherche des Monuments Historiques (Champssur-Marne) for the shearing tests. The authors thank Mathilde Thienot for helpful discussion.

\section{References}

[1] Y. Kamiya, R. Lu, T. Kumamoto, T. Honda, and T. Miyakoshi, "Deterioration of surface structure of lacquer films due to ultraviolet irradiation," Surface and Interface Analysis, vol. 38, no. 9, pp. 1311-1315, 2006.

[2] C. Mc Sharry, R. Faulkner, S. Rivers, M. S. P. Shaffer, and T. Welton, "The chemistry of East Asian lacquer: a review of the scientific literature," Reviews in Conservation, vol. 8, pp. 29-40, 2007.

[3] T. Ogawa, K. Arai, and S. Osawa, "Light stability of oriental lacquer films irradiated by a fluorescent lamp," Journal of Environmental Polymer Degradation, vol. 6, no. 1, pp. 59-65, 1998.

[4] A.-S. Le Hô, C. Duhamel, C. Daher et al., "Alteration of Asian lacquer: in-depth insight using a physico-chemical multiscale approach," Analyst, vol. 138, no. 19, pp. 5685-5696, 2013.

[5] Y. Yamashita, "The plan for the conservation of the Mazarin chest," in Proceedings of the International Course on Conservation of Japanese Lacquer in the Role of Urushi in International Exchange: 27th International Symposium on the Conservation and Restoration of Cultural Property, pp. 159-170, Tokyo National Research Institute for Cultural Property, Tokyo National Museum, Tokyo, Japan, December 2003.

[6] M. Webb, "Methods and materials for filling losses on lacquer objects," Journal of the American Institute for Conservation, vol. 37, no. 1, pp. 117-133, 1998.

[7] M. S. Podmaniczky, "Structural fills for large wood objects: contrasting and complementary approaches," Journal of the American Institute for Conservation, vol. 37, no. 1, pp. 111-116, 1998.

[8] J. Thornton, "A brief history and review of the early practice and materials of gap-filling in the west," Journal of the American Institute for Conservation, vol. 37, no. 1, pp. 3-22, 1998.

[9] S. Lambooy, "Lacquer on Japanese porcelain: a case study of two Imari vases with urushi lacquer decoration from the collection of the Rijksmuseum Amsterdam," in Proceedings of the 14th Triennal Meeting, International Council of Museums Conservation Committee, Ed., vol. 2, pp. 1075-1082, The Hague, The Netherlands, September 2005.

[10] M. H. Carr, "Lacquer loss compensation revisited: more big holes in the top," in Postprints of the Wooden Artifacts Group, 31st Annual Meeting of the American Institute for Conservation, June 2003, pp. 59-65, AIC, Arlington, Tex, USA, 2003.

[11] S. Fukuda, "Japanese lacquered albums, an appraisal of their development, construction and repair," Bookbinder, no. 23, pp. 35-45, 2009.

[12] V. Horie, "Acrylic polymers," in Materials for Conservation, p. 159, Elsevier, Oxford, UK, 2nd edition, 2010.

[13] R. L. Feller, "Standards in the evaluation of thermoplastic resins," in 5th Triennal Meeting: Zagreb, 1-8 October 1978: Preprints, vol. 3, pp. 78/16/4/1-78/16/4/11, International Council of Museums Conservation Committee, Zagreb, Croatia, 1978.

[14] J. H. Hofenk de Graaff, "Hydroxy propyl cellulose, a multipurpose conservation material," in Proceedings of the 6th Triennal Meeting, International Council of Museums Conservation Committee, Ed., vol. 3, pp. 81/14/9-1-81/14/9-7, Ottawa, Canada, September 1981.

[15] K. St. John, "Survey of current methods and materials used for the conservation of leather bookbindings," AIC Book and Paper Group Annual 19, 2000.

[16] J. Brandrup, E. H. Immergut, E. A. Grulke, A. Abe, and D. R. Bloch, Polymer Handbook, John Wiley \& Sons, New York, NY, USA, 2005.

[17] P. Sakellariou, R. C. Rowe, and E. F. T. White, "The thermomechanical properties and glass transition temperatures of some cellulose derivatives used in film coating," International Journal of Pharmaceutics, vol. 27, no. 2-3, pp. 267-277, 1985.

[18] R. F. Landel and L. E. Nielsen, Mechanical Properties of Polymers and Composites, CRC Press, Marcel Dekker, New York, NY, USA, 1994.

[19] Klucel hydroxypropylcellulose in hot-melt extrusion applications, Aqualon, Ashland, http://www.ile.com.cn/UpLoad/file/ 201372315511314020130723035113140.pdf.

[20] K.-J. Kim, S.-B. Lee, and N.-W. Han, "Effects of the degree of crosslinking on properties of poly(vinyl alcohol) membranes," Polymer Journal, vol. 25, no. 12, pp. 1295-1302, 1993.

[21] O. Gordobil, I. Egüés, I. Urruzola, and J. Labidi, "Xylan-cellulose films: improvement of hydrophobicity, thermal and mechanical properties," Carbohydrate Polymers, vol. 112, pp. 56-62, 2014.

[22] P. Pareo, G. L. De Gregorio, M. Manca et al., "Ultra lightweight PMMA-based composite plates with robust super-hydrophobic surfaces," Journal of Colloid and Interface Science, vol. 363, no. 2, pp. 668-675, 2011.

[23] E. Chibowski, L. Hołysz, K. Terpilowski, and M. Jurak, "Investigation of super-hydrophobic effect of PMMA layers with different fillers deposited on glass support," Colloids and Surfaces A: Physicochemical and Engineering Aspects, vol. 291, no. 1-3, pp. 181-190, 2006. 

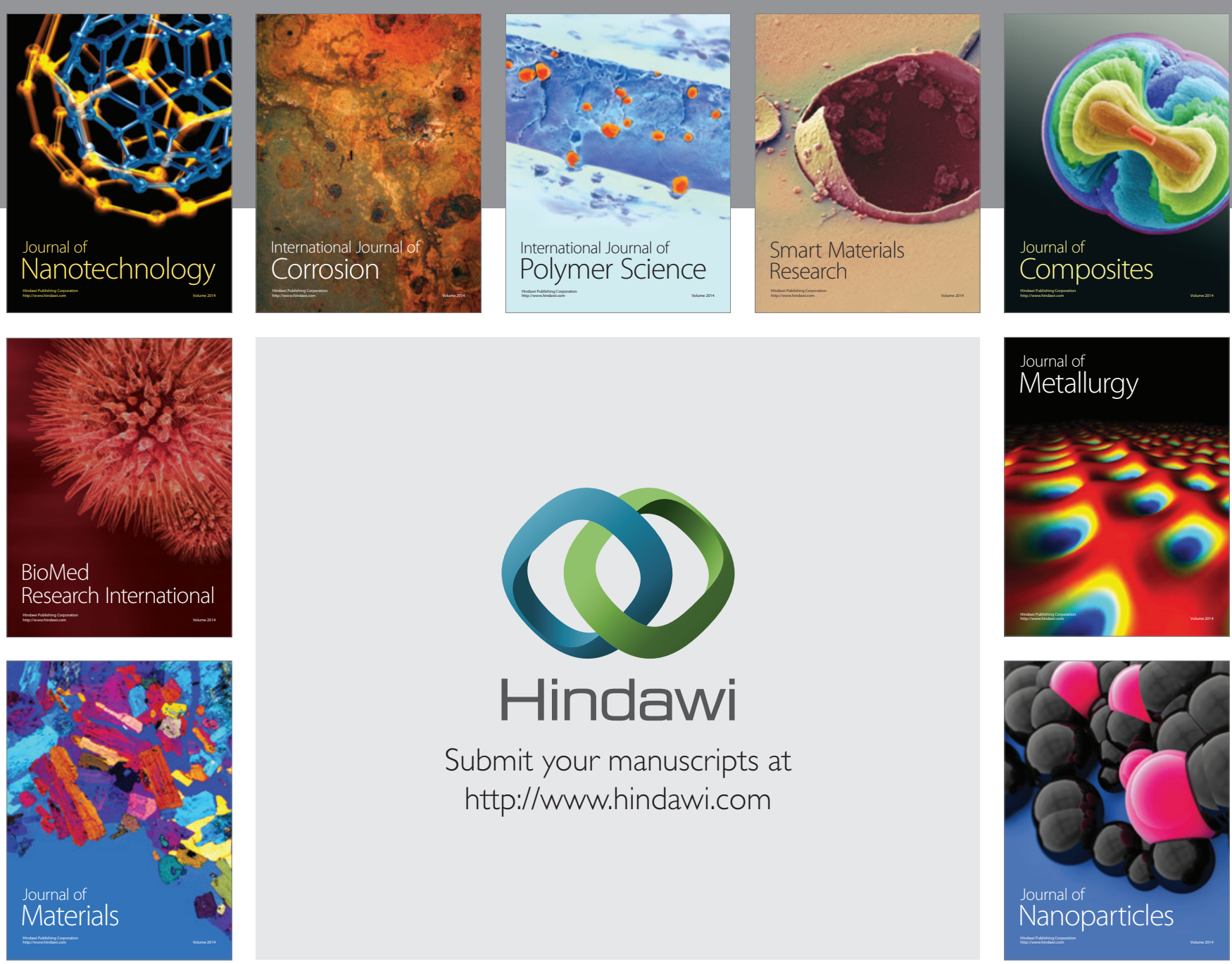

Submit your manuscripts at http://www.hindawi.com
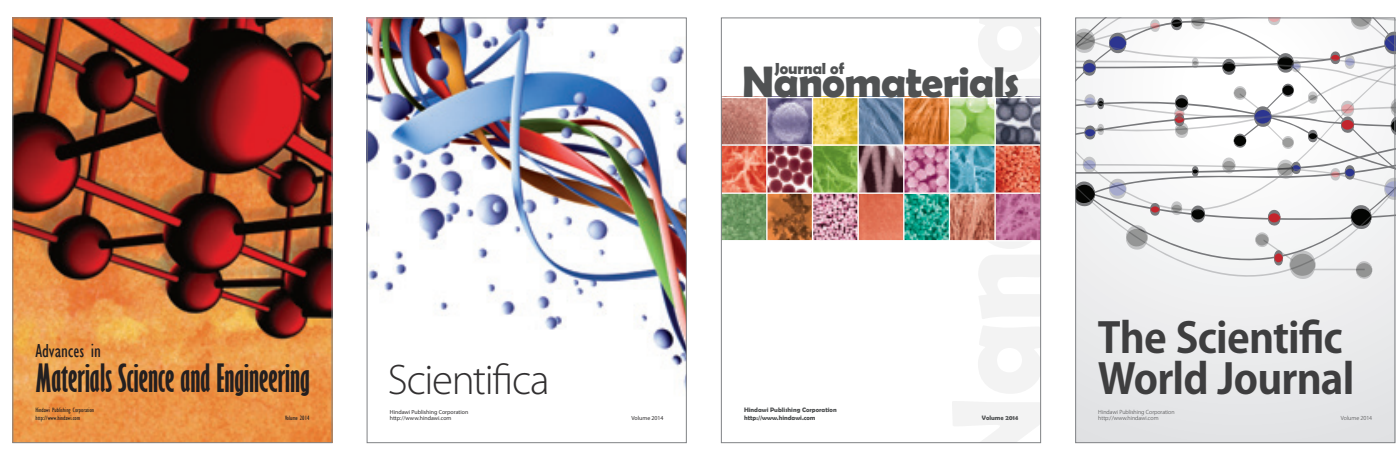

\section{The Scientific World Journal}
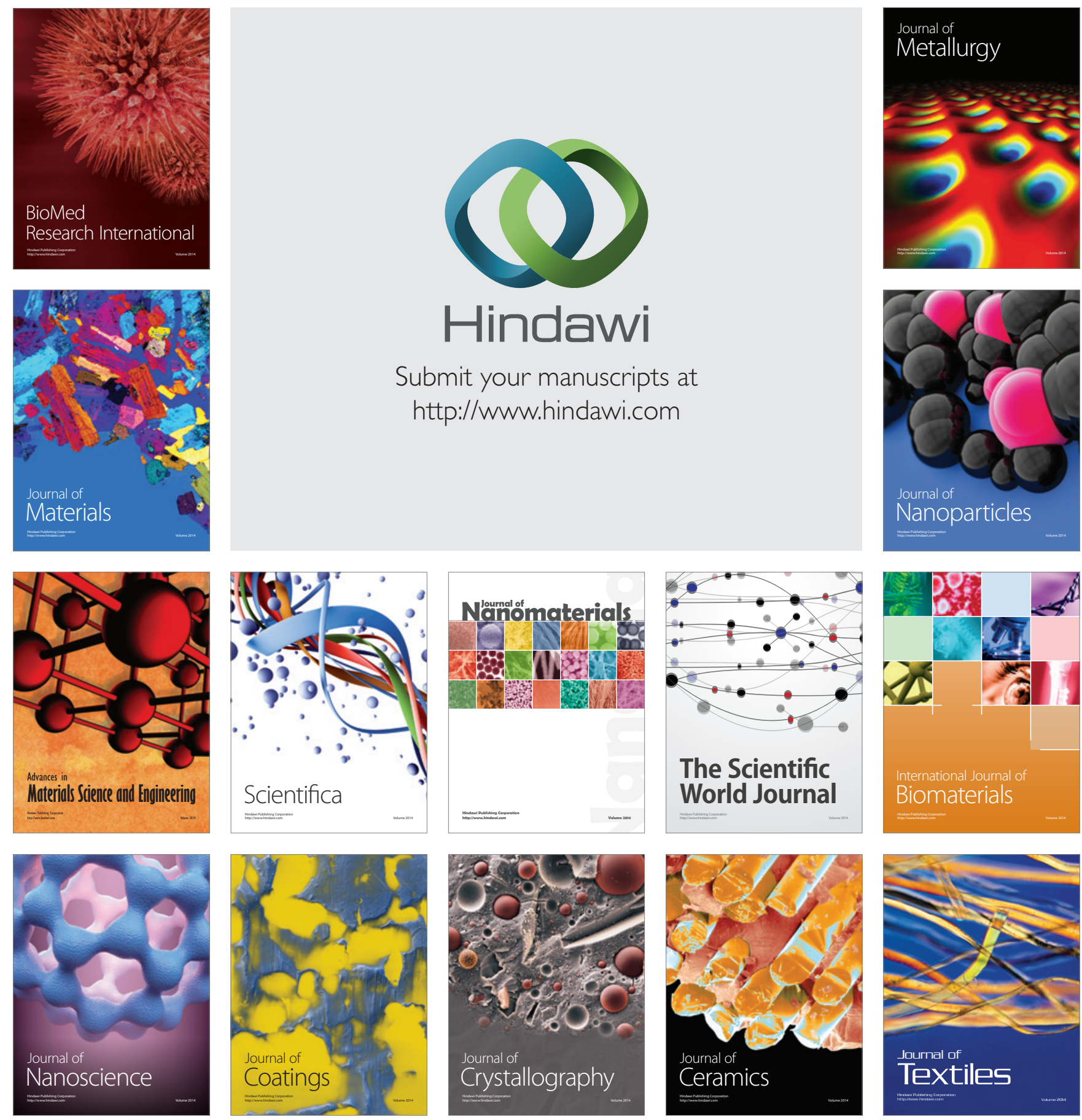